\title{
Endurance Training Damages Small Airway Epithelium in Mice
}

\author{
Laura Chimenti ${ }^{1,2}$, Giuseppe Morici ${ }^{1,2}$, Alessandra Paternò ${ }^{3}$, Anna Bonanno², Liboria Siena ${ }^{2}$, Attilio Licciardi ${ }^{1}$, \\ Mario Veca', Walter Guccione', Filippo Macaluso', Giovanni Bonsignore ${ }^{2}$, and Maria R. Bonsignore ${ }^{2,3}$ \\ 'Department of Experimental Medicine (DIMES), University of Palermo, Italy; ${ }^{2}$ Institute of Biomedicine and Molecular Immunology (IBIM), \\ National Research Council (CNR), Palermo, Italy; and ${ }^{3}$ Department of Medicine, Pneumology, Physiology, and Nutrition (DIMPEFINU), \\ University of Palermo, Italy
}

\begin{abstract}
Rationale: In athletes, airway inflammatory cells were found to be increased in induced sputum or bronchial biopsies. Most data were obtained after exposure to cold and dry air at rest or during exercise. Whether training affects epithelial and inflammatory cells in small airways is unknown.

Objectives: To test whether endurance training under standard environmental conditions causes epithelial damage and inflammation in the small airways of mice.

Methods and Measurements: Formalin-fixed, paraffin-embedded lung sections were obtained in sedentary $(n=14)$ and endurancetrained $(n=16)$ Swiss mice at baseline and after 15,30 , and 45 days of training. The following variables were assessed (morphometry and immunohistochemistry) in small airways (basement membrane length $<1 \mathrm{~mm}$ ): (1) integrity, proliferation, and apoptosis of bronchiolar epithelium; and (2) infiltration, activation, and apoptosis of inflammatory cells.

Main Results: Compared with sedentary mice, bronchiolar epithelium of trained mice showed progressive loss of ciliated cells, slightly increased thickness, unchanged goblet cell number and appearance, and increased apoptosis and proliferation (proliferating cell nuclear antigen) ( $p<0.001$ for all variables). Leukocytes (CD45 $5^{+}$ cells) infiltrated airway walls $(p<0.0001)$ and accumulated within the lumen $(p<0.001)$; however, apoptosis of $C D 45^{+}$cells did not differ between trained and sedentary mice. Nuclear factor-кB trans-

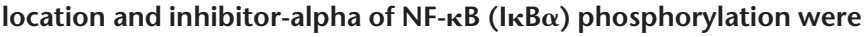
not increased in trained compared with sedentary mice.

Conclusions: Bronchiolar epithelium showed damage and repair associated with endurance training. Training increased inflammatory cells in small airways, but inflammatory activation was not increased. These changes may represent an adaptive response to increased ventilation during exercise.
\end{abstract}

Keywords: exercise; airway damage; remodeling; inflammation; apoptosis

Large airways of athletes exercising in a cold (1-6) or moderate (7-9) environment show evidence of inflammation. In crosscountry skiers, lymphocytes were increased in bronchoalveolar lavage fluid (1), and bronchial biopsies showed inflammation and airway remodeling (3), suggesting chronic airway disease ("ski asthma") (1-5). Sled dogs showed airway damage after intense and prolonged exercise in an extremely cold and dry environment (6). In nonasthmatic runners exercising under moderate environmental conditions, neutrophil counts in induced sputum were increased at rest and after a marathon race (7). Similarly, swimmers and rowers showed predominance of neutrophils in induced sputum at rest and after exercise $(8,9)$.

(Received in original form August 3, 2006; accepted in final form December 21, 2006) Correspondence and requests for reprints should be addressed to Laura Chimenti, Ph.D., Department of Experimental Medicine, University of Palermo, Corso Tukory, 129, 90134 Palermo, Italy. E-mail: chimenti@ibim.cnr.it

Am J Respir Crit Care Med Vol 175. pp 442-449, 2007

Originally Published in Press as DOI: 10.1164/rccm.200608-1086OC on December 21, 2006 Internet address: www.atsjournals.org

\section{AT A GLANCE COMMENTARY}

Scientific Knowledge on the Subject

Studies in endurance athletes of winter and summer sports documented increased inflammatory cells in large airways. However, whether training affects the small airways is unknown.

\section{What This Study Adds to the Field}

Endurance training in mice causes epithelial damage and repair but does not appear to be a powerful proinflammatory stimulus.

Airway inflammation in trained subjects shows some peculiarities, and its significance and mechanisms are under debate. First, airway inflammation was not always associated with bronchial hyperreactivity or postexercise respiratory symptoms $(3,7)$. Second, inflammatory cells were not activated after exercise (7-9), and ski asthma did not respond to inhaled steroids (10). Third, in ovalbumin-sensitized mice, translocation of nuclear factor $(\mathrm{NF})-\kappa \mathrm{B}$ in airway cells was lower in trained than in sedentary animals (11). Therefore, training may blunt inflammatory activation in the airways (12), similar to the effects reported in the systemic compartment $(13,14)$.

Inflammatory cell recruitment into large airways could be triggered by damage of airway epithelium. In vitro, bronchial epithelial cells (BECs) exposed to hyperosmolar medium or cooling-rewarming released chemotactic factors $(15,16)$, suggesting a role of BECs in the "proinflammatory" effects of exercise (12). On the other hand, data obtained in vivo are variable. In large airways of skiers, no clear evidence of epithelial damage was reported despite evidence of remodeling (3). In marathon runners and swimmers, BEC counts in induced sputum were low at rest and after exercise $(7,8)$, but apoptosis of BECs increased after a race (17). Only in rowers after supramaximal exercise did BEC counts in induced sputum tend to increase (9). Conversely, BEC damage occurred in horses after exercise while breathing cold air (18), whereas repeated dry and cold air challenges in dogs caused loss of ciliated epithelium and airway remodeling (19). Thus, at present, no conclusions can be drawn, although in vitro data support the possible involvement of BECs in exercise-induced airway inflammation $(15,16)$.

Whether training affects small airway epithelium is unknown, and such data may provide an insight into the pathophysiology of exercise-induced airway changes and estimate the risk of longterm respiratory effects of training. The aim of this study in endurance-trained mice was to analyze BECs, the occurrence of epithelial remodeling, and inflammatory cell infiltration, activation, and apoptosis in small airways. Some of the results of 
these studies have been previously reported in the form of abstracts (20-22).

\section{METHODS}

\section{Animals}

Male Swiss mice (body weight, $38.0 \pm 3.8 \mathrm{~g} ; 8$ wk old) were maintained in stainless steel wire cages at constant temperature $\left(21^{\circ} \pm 1^{\circ} \mathrm{C}\right)$ and humidity $(60 \pm 5 \%)$ and a 12 -hour light/dark schedule. Food and water were freely available (23-26).

\section{Exercise Training Protocol}

Mice were randomly assigned to sedentary $(n=14)$ or trained $(n=$ 16) groups. Training was performed in the same room where the animals were housed using a motorized rotor (Rota-Rod; Ugo Basile, Biological Research Apparatus, Comerio, Varese, Italy), 5 days/week for 6 weeks at progressively increasing loads (Table 1). Mice were killed (21) at the following times: at $0(\mathrm{n}=5), 15(\mathrm{n}=2), 30(\mathrm{n}=2)$, and 45 days $(\mathrm{n}=5)$ in sedentary animals; and at $15(\mathrm{n}=3), 30(\mathrm{n}=3)$, and 45 days $(\mathrm{n}=10)$ in trained animals. Blood was collected for lymphocyte and neutrophil differential counts (4-5 smears/animal).

\section{Tissue Preparation and Morphometric Analysis}

Lungs were excised, fixed in $4 \%$ formaldehyde, dehydrated, and embedded in paraffin. Rehydrated sections were stained with hematoxylineosin for morphometry. Airway images $(20 \times$ and $40 \times)$ were obtained by a light microscope (Leitz Biomed; Leica, Cambridge, UK) and a video recorder linked to a computerized image system (Quantimet 500 Image Processing and Analysis System, Qwin V0200B software; Leica). On average, five airways per slide were counted (range, 2-7), and only airways with a visible full perimeter were analyzed. Airway basement membrane (BM) was traced, and airways with BM length of greater than $1 \mathrm{~mm}$ were excluded from all analyses. Epithelial area (EA) was measured as the region between BM and lumen, and thickness calculated as the EA/BM ratio. Ciliated and goblet cell counts were normalized for BM length.

\section{Skeletal Muscle after Training}

Fiber diameter of the tibialis anterior muscle was measured on formalinfixed, paraffin-embedded, hematoxylin-and-eosin-stained sections by a computerized image-processing system (Image Pro-plus Software; Media Cybernetics, Silver Spring, MD) (27).

\section{Immunohistochemistry}

Monoclonal antibodies (Santa Cruz Biotechnology, Inc., Santa Cruz, CA) were used to assess the following: leukocytes (anti-CD45), epithelium proliferation (anti-proliferating cell nuclear antigen [antiPCNA]), and inflammatory activation (anti-NF-кB subunit p65, anti-

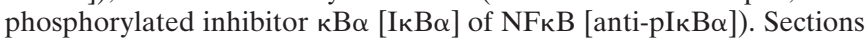
were deparaffinized, incubated with $0.1 \%$ trypsin in tris-buffered saline (TBS), and stained with the respective primary antibody. Immunoreactivity was revealed by the labeled streptavidin biotin alkalinephosphatase technique (Dako Cytomation, Glostrup, Denmark). Sections were counterstained with hematoxylin and blindly read by two investigators (L.C., A.P.). Positive cells were expressed per micrometer

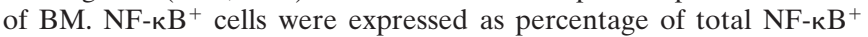
cells. $\mathrm{pI \kappa B} \alpha^{+}$cells were normalized for total $\mathrm{I}_{\kappa} \mathrm{B} \alpha^{+}$cell counts. Alcian blue-PAS staining was used to detect acid and neutral mucin production in goblet cells (28).

\section{TABLE 1. TRAINING PROTOCOL}

\begin{tabular}{lccc}
\hline Week & Session Time $(\mathrm{min})$ & Rotations/min & Length $(\mathrm{m})$ \\
\hline 1 & 15 & 16 & 48 \\
2 & 30 & 16 & 96 \\
3 & 30 & 20 & 120 \\
4 & 45 & 20 & 180 \\
5 & 60 & 20 & 240 \\
6 & 60 & 24 & 288 \\
\hline
\end{tabular}

\section{Detection of Apoptosis}

Apoptosis was assessed in BECs and $\mathrm{CD} 45^{+}$cells in situ by indirect TUNEL (TdT-mediated fluorescein-dUTP nick end labeling; In situ Cell Death Detection kit; AP or POD-Roche Diagnostics, Basel, Switzerland). All sections were lightly stained with hematoxylin and read at $100 \times$ magnification. Apoptotic BECs were expressed per micrometer of BM. Apoptotic CD45 ${ }^{+}$cells were expressed as a percentage of total $\mathrm{CD} 45^{+}$cells in the examined airway wall.

\section{Statistical Analysis}

Results are reported as mean $\pm \mathrm{SD}$. Analysis of variance (ANOVA) and Bonferroni's correction for post hoc comparisons were used to test for differences between sedentary and trained mice at different time points. Time trends were assessed by linear regression (Statview 5.0.1; SAS Institute, Inc., Cary, NC). Significance was at $p<0.05$.

\section{RESULTS}

\section{Systemic Effects of Training}

At 45 days, body weight was lower in trained $(44.1 \pm 7.1 \mathrm{~g})$ than in age-matched sedentary mice $(48.4 \pm 1.9 \mathrm{~g}, \mathrm{p}<0.05)$. For muscle hypertrophy, mean fiber diameter of the tibialis anterior muscle was significantly $(+26 \%)$ greater in trained mice (results already reported in Reference 27).

\section{Damage, Proliferation, and Apoptosis of Bronchiolar Epithelium}

In sedentary control animals, no significant difference was found between Time 0 and subsequent time points for any variable, and pooled data were used for comparisons versus trained mice.

Figures 1 and 2 show the morphologic data obtained in sedentary and 45-day-trained mice. Figure 3 illustrates the time course of the same variables as in Figures 1 and 2 during training. The bronchiolar epithelium showed progressive changes during training. At 45 days, the number of ciliated epithelial cells was fourfold lower in trained $(0.03 \pm 0.01$ cells $/ \mu \mathrm{m} \mathrm{BM})$ compared with sedentary mice $(0.12 \pm 0.02$ cells $/ \mu \mathrm{m}$ BM, p $<0.0001)$ (Figures 1A and 1B; Figure 3A). Total epithelial cell counts were similar in sedentary and trained mice at all time points (ANOVA), but cell counts in trained animals showed a weak trend toward a progressive increase $\left(R^{2}=0.125, \mathrm{p}<0.05\right.$; data not shown).

At 45 days, epithelial thickness was $56 \%$ greater in trained (EA/BM: $25.8 \pm 8.2 \mu \mathrm{m})$ than in sedentary mice $(16.5 \pm 4.1$ $\mu \mathrm{m}, \mathrm{p}<0.0003$ ) (Figures $1 \mathrm{C}$ and 1D; Figure 3B), and apoptosis of BECs almost doubled $(0.08 \pm 0.01$ cells $/ \mu \mathrm{m} \mathrm{BM}$ in trained mice vs. $0.05 \pm 0.01$ cells $/ \mu \mathrm{m} \mathrm{BM}$ in sedentary controls, $\mathrm{p}<$ 0.0001) (Figures 2A and 2B; Figure 3C). Bronchiolar epithelium showed a fivefold increase in the number of proliferating cells $(0.063 \pm 0.041$ cells $/ \mu \mathrm{m} \mathrm{BM})$ compared with sedentary animals $(0.013 \pm 0.011$ cells/ $\mu \mathrm{m} \mathrm{BM}, \mathrm{p}<0.001)$, suggesting active repair (Figures 2C and 2D; Figure 3D).

Goblet cell counts were unaffected by training (graph in Figure 4). Alcian blue-PAS staining was negative at all time points in both sedentary and trained mice, indicating no shift toward acid or neutral mucin production during training (Figures 4A and 4B).

\section{Inflammatory Cells}

No difference was found between trained and sedentary mice in blood lymphocyte and neutrophil differential counts at any time point (27). In bronchioles of mice trained for 45 days, leukocyte counts were fivefold higher than in sedentary control animals in both wall (trained: $0.071 \pm 0.006 \mathrm{CD} 45^{+}$cells $/ \mu \mathrm{m}$ BM; sedentary: $0.014 \pm 0.001 \mathrm{CD}^{+} 5^{+}$cells $/ \mu \mathrm{m} \mathrm{BM}, \mathrm{p}<0.0001$; Figures 5A and 5B) and lumen (trained: $0.010 \pm 0.005 \mathrm{CD}^{+} 5^{+}$ 

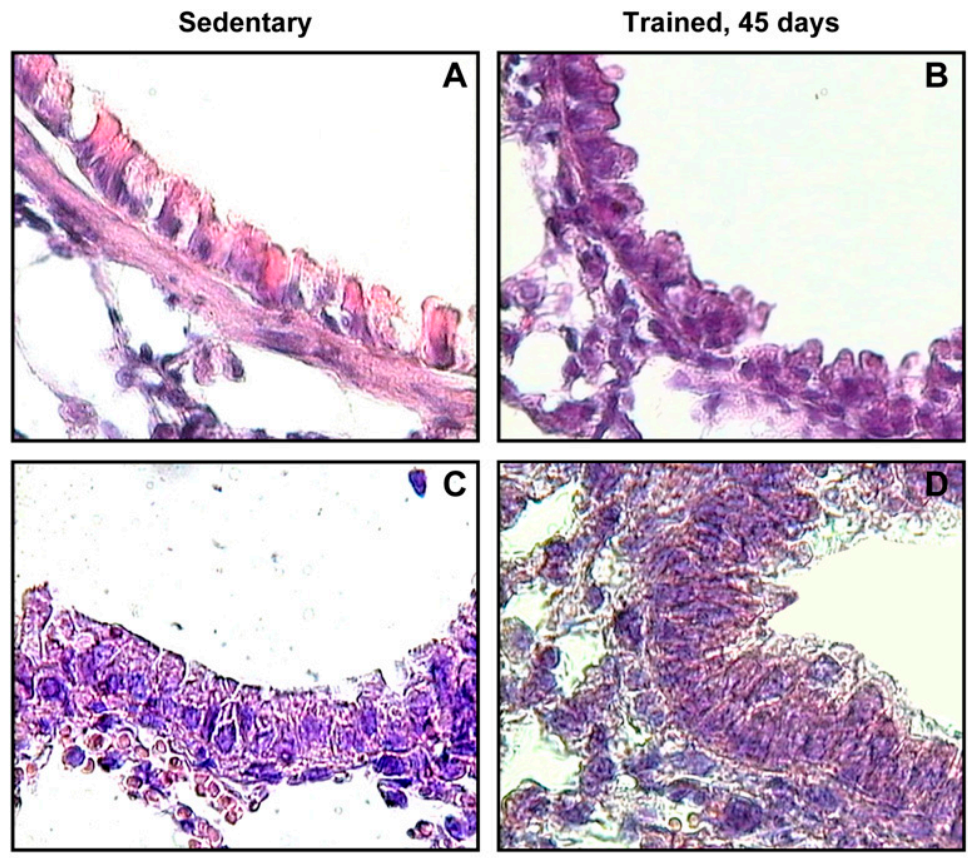
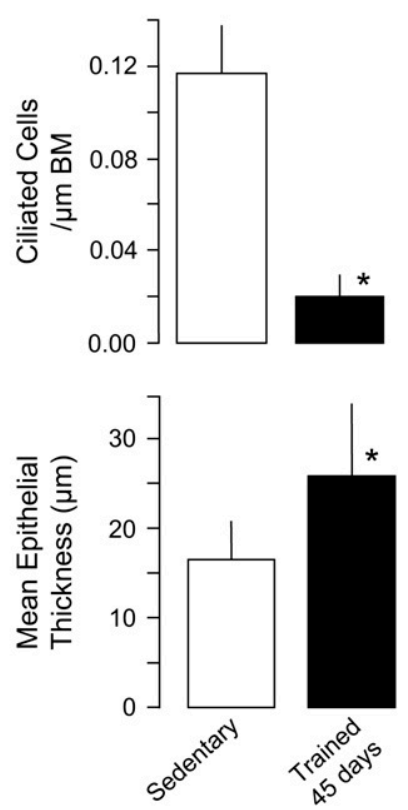

Figure 1. Hematoxylin-eosin staining (original magnification, $40 \times$ ) of bronchiolar transverse sections $(A-D)$. Quantitative data analysis is shown in the bar graphs on the right (mean \pm SD of three experiments; ${ }^{*} p<0.001$ between sedentary and trained groups). Bronchiolar epithelium showed a normal appearance in sedentary mice $(A$ and $C)$, whereas loss of cilia ( $B$ and upper bar graph) and increased epithelium thickness ( $D$ and lower bar graph) were evident in 45-day-trained mice. cells/ $\mu \mathrm{m} \mathrm{BM;} \mathrm{sedentary:} 0.002 \pm 0.001 \mathrm{CD} 45^{+}$cells/ $\mu \mathrm{m} \mathrm{BM}$ $\mathrm{p}<0.001)$. Absolute $\mathrm{CD} 45^{+}$cells counts in lumen, however, were much lower than in the airway wall (Figures 5C and 5D). The time course of $\mathrm{CD} 45^{+}$cell counts and apoptosis is shown in Figure 6: $\mathrm{CD} 45^{+}$cells progressively increased both in bronchiolar wall and lumen, but the percentage of apoptotic CD $45^{+}$ cells did not change over time and remained similar to that of sedentary animals.

\section{Markers of Inflammatory Activation}

NF- $\kappa \mathrm{B}$ translocation and IкB $\alpha$ phosphorylation, both as markers of inflammatory activation in the airways, were assessed in
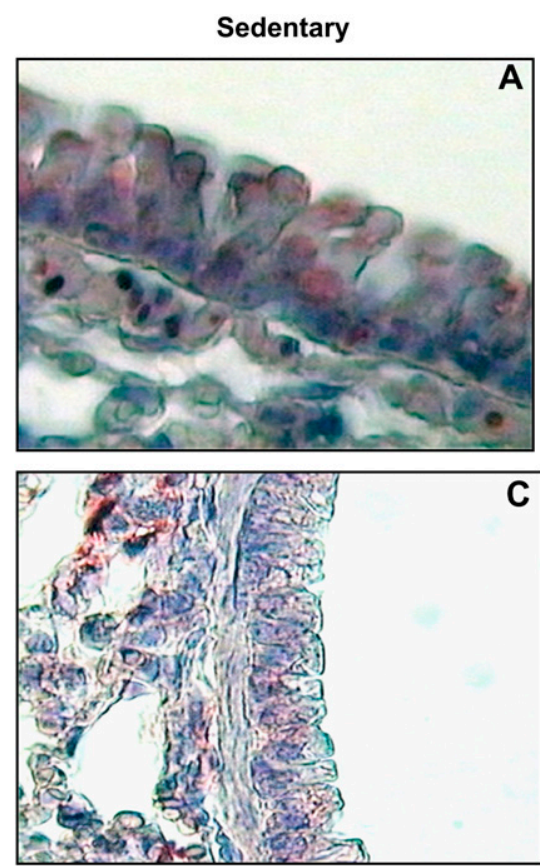
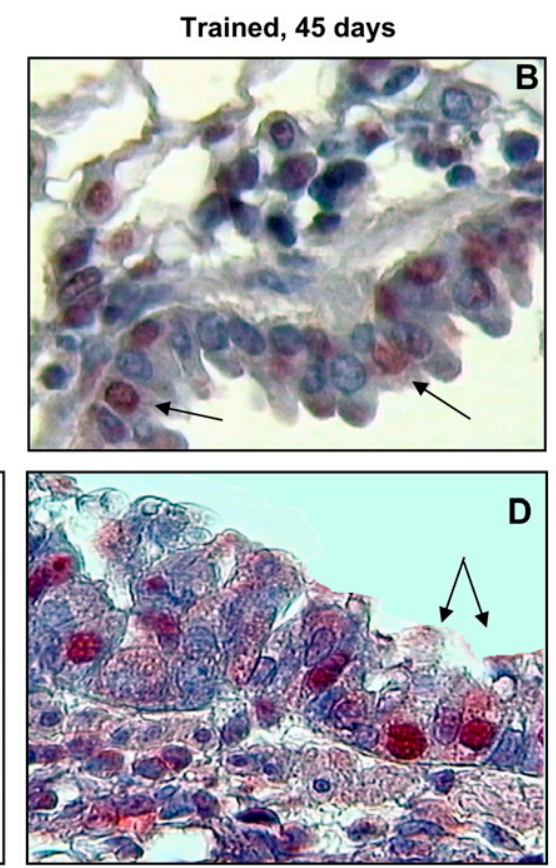
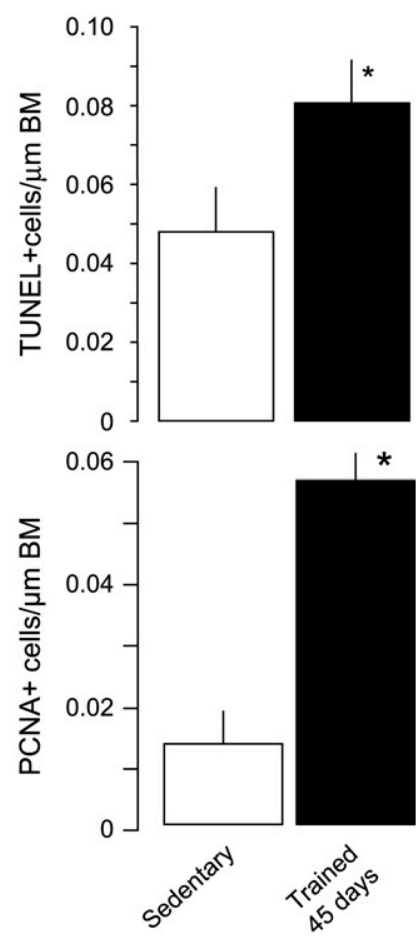

Figure 2. Immunohistochemical staining (original magnification, 40×) of bronchiolar epithelial cells for apoptosis (TdT-mediated fluorescein-dUTP nick end labeling [TUNEL]; $A$ and $B$ ) and proliferation (proliferating cell nuclear antigen [PCNA]; $C$ and $D$ ). Quantitative data analysis is shown in the bar graphs on the right (mean \pm SD of three experiments; ${ }^{*} p<0.001$ between sedentary and trained groups). Sedentary mice showed normal bronchiolar epithelium $(A$ and $C$ ), whereas 45-day-trained mice showed increased apoptosis (arrows in $B$ and upper bar graph) and proliferation (arrows in $D$, and lower bar graph). 

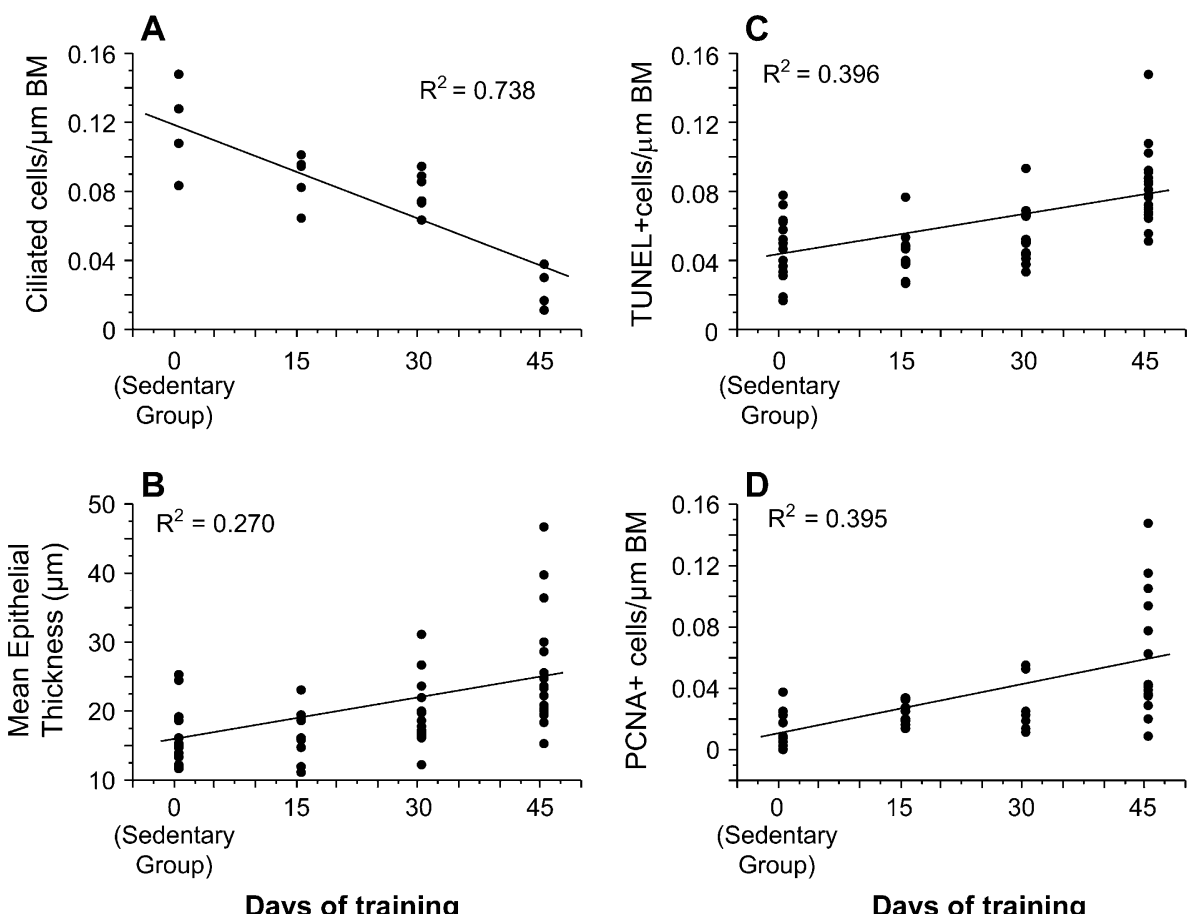

Days of training

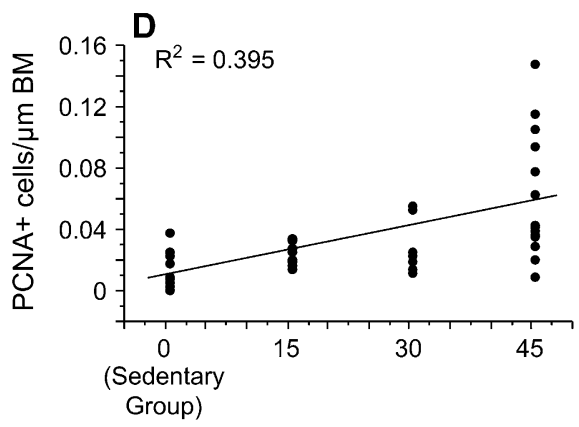

Days of training
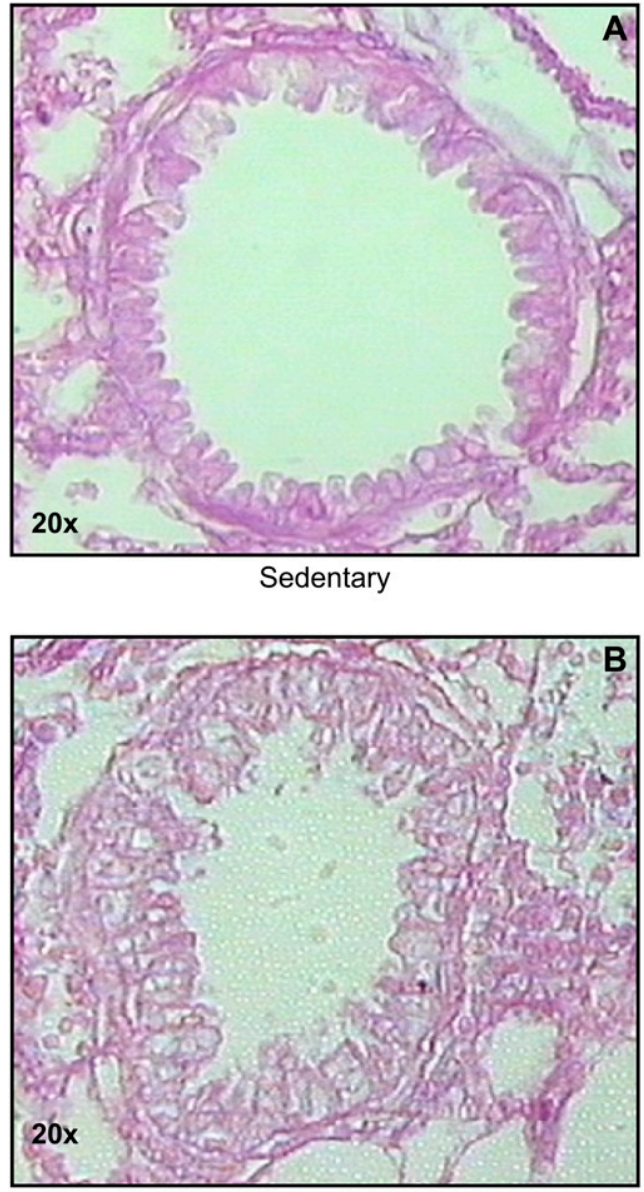

Trained, 45 days

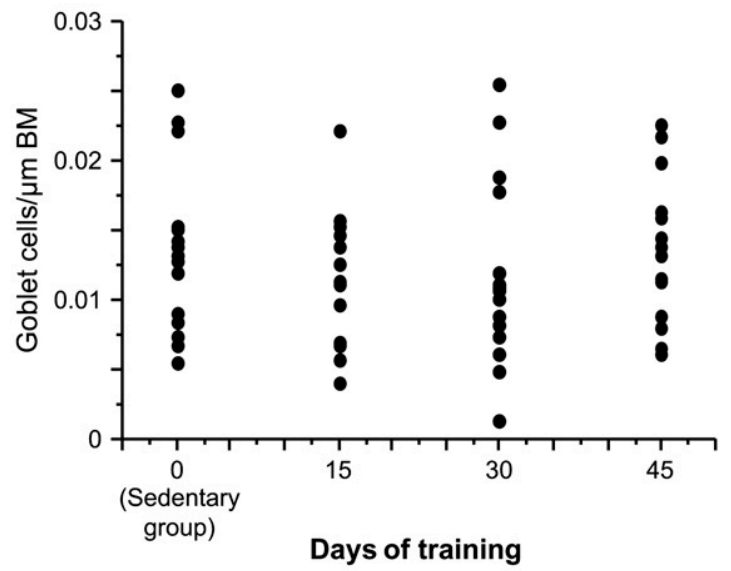

Figure 4. Alcian blue-periodic acid-Schiff staining of bronchioles was negative in both sedentary $(A)$ and 45-day-trained (B) mice. The graph on the right shows goblet cell counts obtained at different time points during the protocol: sedentary and trained mice showed similar results at all times.
Figure 3. Time course of epithelial changes during training. Ciliated cells progressively detion $(D)$ increased as training duration increased. All regressions were significant at $p<$ $0.05 . \mathrm{BM}=$ basement membrane. 

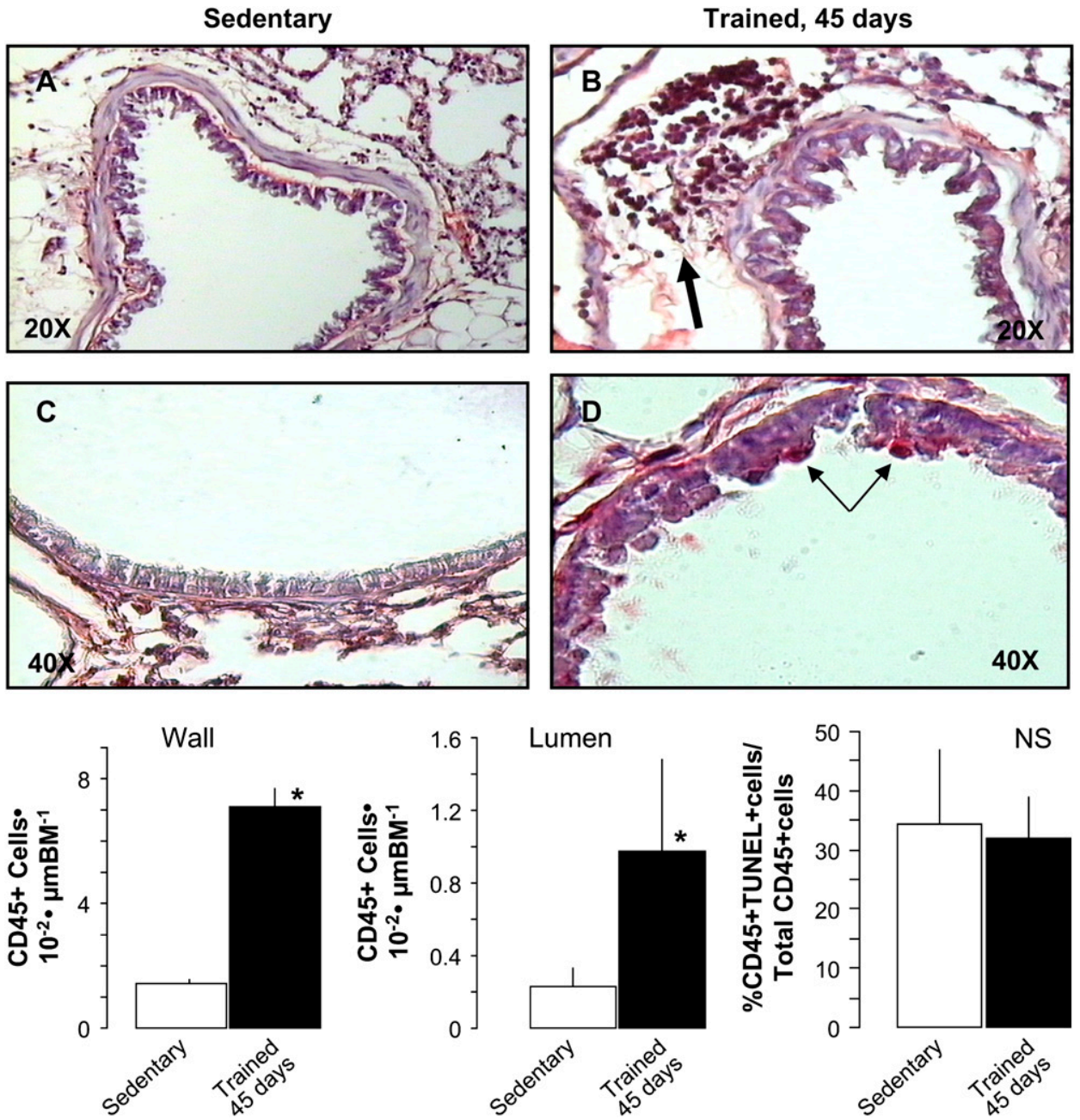

Figure 5. Immunohistochemistry for inflammatory $\left(\mathrm{CD}_{4} 5^{+}\right)$cell infiltration in small airways. In lung sections from sedentary ( $A$ and $C$; original magnification, $20 \times$ and $40 \times$, respectively) and trained mice ( $B$ and $D$; original magnification, $20 \times$ and $40 \times$, respectively), CD45 ${ }^{+}$cells can be identified in the bronchiolar walls $(B$, large arrow) and the luminal side $(D$, small arrows). Bargraphs show the quantitative analysis (mean \pm SD of three independent experiments; * $p<0.0001$ between sedentary and 45-d-trained mice) of $\mathrm{CD}_{4} 5^{+}$cells in airway wall (left graph) and airway lumen (middle graph). The percentage of apoptotic CD45 ${ }^{+}$cells (TUNEL assay) was similar in sedentary and 45-day-trained mice (right graph, not significant $[N S])$. sedentary and trained mice by immunohistochemistry. At all time points, training did not significantly affect translocation of the NF-кB subunit p65 (Figure 7, left) or phosphorylation of Iк $\mathrm{B} \alpha$ (Figure 7, right) in small airways.

\section{DISCUSSION}

Although previous studies have shown increased inflammatory cells in large airways of endurance athletes (1-9), little is known regarding small airway cells after training. To fill this gap, we have trained normal mice according to a low-moderate intensity protocol to study the effects of training on small airways, with a focus on epithelial and inflammatory cells in bronchiolar wall and lumen. Training for 45 days caused progressive damage, apoptosis, and proliferation of bronchiolar epithelium, associated with leukocyte influx into airway wall and lumen. Goblet cells or apoptosis of leukocytes were unaffected by training. Markers of inflammatory activation, such as translocation of $\mathrm{NF}-\kappa \mathrm{B}$ into the nucleus of inflammatory cells, or phosphorylation of the NF- $\kappa \mathrm{B}$ inhibitor I $\mathrm{B} \alpha$, were not increased in airway leukocytes of trained animals. Therefore, endurance training caused epithelial damage and repair, but did not appear to be a powerful proinflammatory stimulus, which is in agreement with previous studies $(7-9,12)$.

The effects of exercise training on small airways have not been studied in detail. In humans, such data are hard to obtain, due to the need to use invasive methods. In addition, studies in animals have mainly tested the hypothesis that exposure to cold and dry air affected bronchial epithelium, either at rest (dog [19]) or during exercise (horse [18]). Such data do not allow inferences about the effects of exercise training per se on small airway cells. Pastva and coworkers examined the effects of training in a model of bronchial asthma, and reported a dramatic improvement in airway inflammation in ovalbumin-sensitized mice undergoing an endurance protocol (11). This study, however, only partly reported the findings obtained in nonsensitized sedentary and trained groups.

The novel finding of our study in normal mice is that bronchiolar epithelium showed progressive decrease in the number of ciliated cells during low- to moderate-intensity training, together with evidence of active repair, indicated by the increase in epithelial thickness and proliferation. Epithelial damage in trained mice was associated with increased apoptosis of BECs. Preliminary data obtained in nonasthmatic runners within 24 hours after a running race also showed increased apoptosis of BECs compared with resting conditions (17). Epithelial proliferation also occurred, as shown by analysis of PCNA, a protein synthesized in early G1 and S phases functioning in cell cycle progression, and DNA replication/repair $(29,30)$. Because translocation of NF- $\mathrm{B}$ in bronchiolar epithelium did not differ between sedentary and trained mice, increased apoptosis of BECs after training appeared to reflect damage rather than a mechanism limiting inflammatory activation $(31,32)$. Overall, the data suggest that 

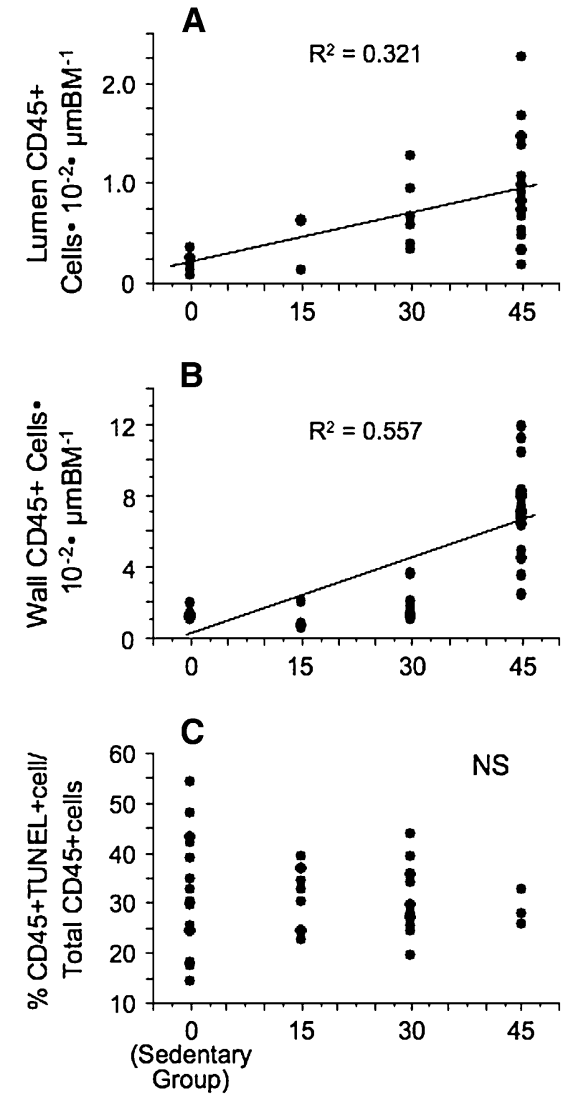

Days of training

Figure 6. Time course of $\mathrm{CD} 45^{+}$cell counts in bronchiolar wall $(A)$, and lumen $(B)$ and percentage of apoptotic cells $(C)$ during training. $\mathrm{CD} 45^{+}$cells increased in both airway wall and lumen as training duration increased ( $p<0.05$ for both). Apoptotic $C D 45^{+}$cells as a fraction of total $\mathrm{CD} 45^{+}$cells were not affected by training (NS).

habitual exercise at incremental loads may increase epithelial turnover in bronchioles.

Remodeling is an alteration in the size, mass, or number of tissue structural components that occurs during growth or in response to injury and/or inflammation. Injury to epithelial surface is normally accompanied by mitotic activity of the remaining cells and rapid restoration of the denuded surface (33). Evidence of exercise-induced airway remodeling similar to that seen in asthma has been demonstrated in skiers (3) and in dogs exercising in cold weather (6). Our data are in line with these results. The changes observed in trained mice were similar to the epithelial damage described in horses after exercise while breathing cold and dry air (18) and in dogs challenged at rest with dry air insufflation in a pulmonary segment (19). To the best of our knowledge, our study is the first to show changes in airway cells suggestive of airway remodeling together with evidence of training effects (i.e., lower body weight and increased muscle mass in trained vs. sedentary mice).

Regarding the mechanism(s) involved in the pathogenesis of epithelial changes, intense exercise hyperpnea can affect airway epithelium by causing changes in viscosity, tonicity, or amount of the airway lining fluid (34). It is also possible that high airflows during exercise may cause epithelial shear stress, although this hypothesis is little considered in the current literature on the effects of exercise on airway cells (35). Structure, function, and metabolism of lung cells are influenced by physical forces (36, 37 ), and inappropriate physical forces, such as mechanical ventilation in an inhomogeneous lung, may induce lung injury (38, 39). We speculate that a similar mechanism may be operating at the small airway level, because repeated stretching of BECs in vitro under conditions of mild hyperosmolar exposure caused IL-8 release (M.R.B., unpublished data). After all-out rowing, which requires very high ventilation, BECs in induced sputum tended to increase, suggesting a potential link between maximal airflows or increased airway stretch during exercise and epithelial damage (9).

Our experiments were not designed to assess whether training may modulate bronchial responsiveness. The mild increase in load during training makes an increase in airway responsiveness unlikely, because bronchial hyperreactivity in nonasthmatic human athletes tends to be associated with very intense and competitive training. In nonasthmatic amateur runners, the response to methacholine in the absence of deep breaths at rest was actually lower than in matched sedentary control subjects, and decreased further after a marathon race (40). Therefore, in addition to inducing bronchoconstriction, endurance exercise may also decrease bronchial responsiveness, possibly by a remodeling effect on airway smooth muscle (40).

Trained mice showed increased leukocyte infiltrate in bronchiolar walls, in line with the findings obtained in samples from large airways in human athletes of different disciplines (1-9). We speculate that exercise may cause influx of inflammatory cells into the airways secondary to epithelial changes. BECs might be affected by osmotic changes or cooling-rewarming during exercise, and trigger an inflammatory cascade by increasing the expression of chemotactic factors, such as IL- 8 and RANTES (regulated upon activation, normal T-cell expressed and secreted), which contribute to the recruitment of inflammatory cells into airways $(15,16)$. However, the increase in inflammatory cells in the lumen could also represent a relevant mechanism to limit inflammation. During an inflammatory event, excessive accumulation of leukocytes can be prevented by a fine balance of immune cell recruitment and removal in the damaged tissue. Apoptosis is a mechanism that is potentially useful in removing granulocytes during inflammation $(41,42)$, but apoptosis of $\mathrm{CD} 45^{+}$cells was similar in trained and sedentary mice.
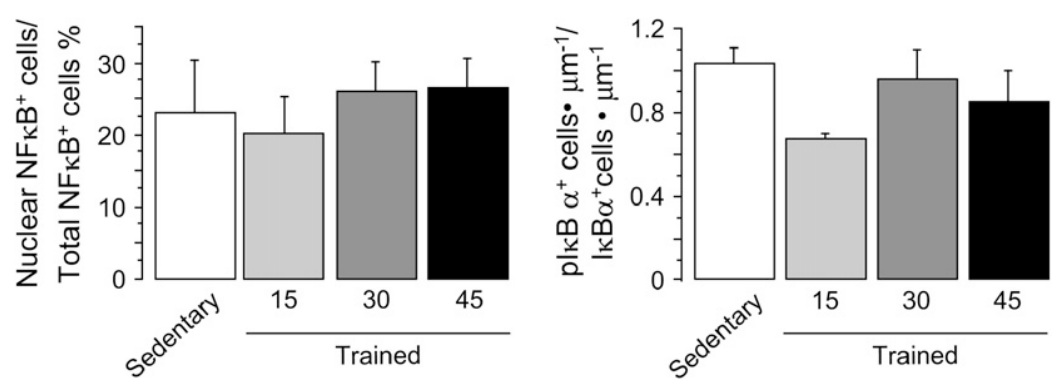

Figure 7. No significant difference was found between sedentary and trained mice in the number of cells showing nuclear factor (NF)- $\mathrm{k}$ translocation (left) or $\mathrm{I}_{\kappa} \mathrm{B} \alpha$ phosphorylation (right). The means of three independent experiments at each time point are shown. 
Therefore, leukocyte influx into the lumen could be interpreted as contributing to inflammatory cell elimination, similar to other diseases characterized by leukocyte migration and accumulation within the lumen $(43,44)$. We speculate that transepithelial migration may be a highly efficient mechanism, alternative to apoptosis, for clearance of mucosal granulocytes $(43,45)$.

Increased inflammatory cells in induced sputum of athletes showed no evidence of activation at rest or after exercise, suggesting a state of "frustrated" inflammation in the conducting airways (12). Goblet cells in bronchioles of our trained mice were negative using Alcian-PAS staining, in line with the lack of evidence of inflammatory activation. In ovalbumin-sensitized mice, PAS-positive cells were increased compared with control animals, but decreased after training (11). Because NF- $\kappa \mathrm{B}$ is a major transcription factor for many inflammatory mediators, we evaluated whether the NF-кB pathway might be affected by exercise training. In nonstimulated cells, the heterodimeric $\mathrm{NF}-\kappa \mathrm{B}$ complexes are sequestered in the cytoplasm by the inhibitory proteins of the IкB family, including I $\mathrm{I} B \alpha(46,47)$. In response to a large variety of stimuli, $\mathrm{I} \kappa \mathrm{B} \alpha$ is rapidly phosphorylated and degraded, allowing NF- $\kappa \mathrm{B}$ nuclear translocation, DNA binding, and transcription of target genes $(48,49)$. Training did

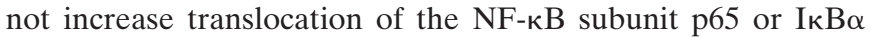
phosphorylation, suggesting blunted or absent activation of inflammatory cells in small airways of trained mice. This finding confirms the data by Pastva and coworkers (11) in nonsensitized mice, who showed that IкB $\alpha$ phosphorylation was lower in trained compared with sedentary animals. Overall, an increase in the number of inflammatory cells without activation suggests that the observed "inflammation" might represent a training adaptation, not necessarily implying detrimental effects for respiratory health. In the systemic compartment, inflammatory activation also appears tightly regulated (13), and decreased progressively during training (14).

Our study has some limitations. First, we did not address whether the reported changes were reversible after interruption of training. This is a relevant clinical question for both healthy subjects and patients undergoing rehabilitation programs. In particular, further studies should address the issue of a possible intensity/duration threshold of exercise beyond which exerciseinduced airway changes may be detrimental and/or irreversible. Second, analysis of large airway epithelium, complete characterization of $\mathrm{CD} 45^{+}$cells, and bronchoalveolar lavage fluid were not obtained in our study. Finally, physiologic measurements, such as oxygen consumption or bronchial reactivity, were not obtained, and the effects of training were estimated based on skeletal muscle hypertrophy. Accurate dose-response relationships between amount/intensity of training and morphologic/ functional changes in small airways deserve further study.

In conclusion, mild- to moderate-intensity endurance training under standard conditions caused loss of ciliated epithelial cells, increased apoptosis, and active repair of bronchial epithelium in the small airways. Inflammatory cells increased in number, but did not appear activated after training, similar to data obtained in induced sputum samples from human athletes. Leukocyte apoptosis was unaffected by training, suggesting that migration into the airway lumen might be the preferential mechanism for clearance of mucosal inflammatory cells. These training-induced changes may represent a physiologic adaptive response to increased ventilation during exercise, but further studies are necessary to assess the threshold for their appearance, their reversibility when training is interrupted, and the potential consequences on respiratory health.

Conflict of Interest Statement: None of the authors has a financial relationship with a commercial entity that has an interest in the subject of this manuscript.
Acknowledgment: The authors thank Filippo Cucinella, Ph.D., and Paolo Muratore, M.Sc., who helped with mouse training and physiologic measurements.

\section{References}

1. Sue-Chu M, Larsson L, Moen T, Rennard SI, Bjermer L. Bronchoscopy and bronchoalveolar lavage findings in cross-country skiers with and without "ski asthma." Eur Respir J 1999;13:626-632.

2. Provost-Craig MA, Arbour KS, Sestili DC, Chabalko JJ, Ekinci E. The incidence of exercise-induced bronchospasm in competitive figure skaters. J Asthma 1996;33:67-71.

3. Karjalainen EM, Laitinen A, Sue-Chu M, Altraja A, Bjermer L, Laitinen LA. Evidence of airway inflammation and remodeling in ski athletes with and without bronchial hyperresponsiveness to methacholine. Am J Respir Crit Care Med 2000;161:2086-2091.

4. Sue-Chu M, Karjalainen EM, Altraja A, Laitinen A, Laitinen LA, Noess AB, Larsson L, Bjermer L. Lymphoid aggregates in endobronchial biopsies from young elite cross-country skiers. Am J Respir Crit Care Med 1998;158:597-601.

5. Larsson K, Ohlsen P, Larsson L, Malmberg P, Rydstrom PO, Ulriksen H. High prevalence of asthma in cross country skiers. BMJ 1993; 307:1326-1329.

6. Davis MS, McKiernan B, McCullough S, Nelson S Jr, Mandsager RE, Willard M, Dorsey K. Racing Alaskan sled dogs as a model of "ski asthma." Am J Respir Crit Care Med 2002;166:878-882.

7. Bonsignore MR, Morici G, Riccobono L, Insalaco G, Bonanno A, Profita M, Paternò A, Mirabella A, Vassalle C, Vignola AM. Airway inflammation in non-asthmatic amateur runners. Am $J$ Physiol 2001;281:L668-L676.

8. Bonsignore MR, Morici G, Riccobono L, Profita M, Bonanno A, Paternò A, Di Giorgi R, Chimenti L, Insalaco G, Cuttitta G, et al. Airway cells after swimming outdoors or in the sea in nonasthmatic athletes. Med Sci Sports Exerc 2003;35:1146-1152.

9. Morici G, Bonsignore MR, Zangla D, Riccobono L, Profita M, Bonanno A, Paternò A, Di Giorgi R, Mirabella F, Chimenti L, et al. Airway cell composition at rest and after an all-out test in competitive rowers. Med Sci Sports Exerc 2004;36:1723-1729.

10. Sue-Chu M, Karjalainen EM, Laitinen A, Larsson L, Laitinen LA, Bjermer L. Placebo-controlled study of inhaled budesonide on indices of airway inflammation in bronchoalveolar lavage fluid and bronchial biopsies in cross-country skiers. Respiration (Herrlisheim) 2000; 67:417-425.

11. Pastva A, Estell K, Schoeb TR, Atkinson P, Schwiebert LM. Aerobic exercise attenuates airway inflammatory responses in a mouse model of atopic asthma. J Immunol 2004;172:4520-4526.

12. Bonsignore MR, Morici G, Vignola AM, Riccobono L, Bonanno A, Profita M, Abate P, Scichilone N, Amato G, Bellia V, et al. Increased airway inflammatory cells in athletes: what do they mean [review]? Clin Exp Allergy 2003;33:14-21.

13. Ostrowski K, Rohde T, Asp S, Schjerling P, Pedersen BK. Pro- and antiinflammatory cytokine balance in strenuous exercise in humans. $J$ Physiol 1999;515:287-291.

14. Suzuki K, Totsuka M, Nakaj S, Yamada M, Kudoh S, Liu Q, Sugawara K, Yamaya K, Sato K. Endurance exercise causes interaction among stress hormones, cytokines, neutrophil dynamics, and muscle damage. J Appl Physiol 1999;87:1360-1367.

15. Hashimoto S, Matsumoto K, Gon Y, Nakayama T, Takeshita I, Horie T. Hyperosmolarity-induced interleukin- 8 expression in human bronchial epithelial cells through p38 mitogen-activated protein kinase. Am J Respir Crit Care Med 1999;159:634-640.

16. Hashimoto S, Gon Y, Matsumoto K, Takeshita I, Maruoka S, Horie T. Inhalant corticosteroids inhibit hyperosmolarity-induced, and cooling and rewarming-induced interleukin- 8 and RANTES production by human bronchial epithelial cells. Am J Respir Crit Care Med 2000;162:1075-1080.

17. Bonsignore MR, Chimenti L, Paternò A, Vultaggio M, Bonanno A, Bellia V, Bonsignore G, Morici G. Longitudinal changes and apoptosis in induced sputum cells in long-distance runners [abstract]. Proc Am Thorac Soc 2006;3:A485.

18. Davis MS, Lockard AJ, Marlin DJ, Freed AN. Airway cooling and mucosal injury during cold weather exercise. Equine Vet J Suppl 2002; 34:413-416.

19. Davis MS, Schoefield B, Freed AN. Repeated peripheral airway hyperpnea causes inflammation and remodelling in dogs. Med Sci Sports Exerc 2003;35:608-616. 
20. Bonsignore MR, Chimenti L, Paternò A, Siena A, Di Felice V, Bonanno A, Macaluso F, Guccione W, Mirabella A, Vignola AM, et al. Endurance training increases inflammatory cells in small airways of mice [abstract]. Proc Am Thorac Soc 2005;2:A496.

21. Chimenti L, Paternò A, Di Felice V, Bonanno A, Licciardi A, Veca M, Guccione W, Di Bella M, Siena A, Farina F, et al. Endurance training damages small airway epithelium in mice [abstract]. Eur Respir J 2005;26(Suppl 49):483s.

22. Chimenti L, Morici G, Paternò A, Siena L, Bonanno A, Licciardi A, Veca M, Di Bella M, Gagliardo R, Bellia V, et al. Increased numbers of inflammatory cells but decreased activation of $\mathrm{NF} \kappa \mathrm{B}$ pathway in small airways of endurance-trained mice. Eur Respir J 2006;28(Suppl $50): 855 \mathrm{~s}$.

23. Attuazione della direttiva $86 / 609 / \mathrm{CEE}$ in materia di protezione degli animali utilizzati a fini sperimentali o ad altri fini scientifici. Decreto legislativo 27 gennaio 1992;116. (cosi come modificato dall'Avviso di Rettifica pubblicato dalla Gazzetta ufficiale della Repubblica Italiana 294;15/12/1992 e dal Decreto del Ministro della Sanità Garavaglia del 22/12/1993).

24. Giles AR. Guidelines for the use of animals in biomedical research. Thromb Haemost 1987;58:1078-1084.

25. National Academy of Sciences. Guide for the care and use of laboratory animals. Washington, DC: National Academy Press; 1996.

26. Report of the American Veterinary Medicine Association Panel on Euthanasia. J Am Vet Med Assoc 2001;218:669-696.

27. Di Felice V, Macaluso F, Montalbano A, Marino Gammazza A, Palumbo D, Angelone T, Bellafiore M, Farina F. Effects of conjugated linoleic acid and endurance training on peripheral blood and bone marrow of trained mice. J Strength Cond Res (In press)

28. Trifilieff A, El-Hashim A, Bertrand C. Time course of inflammatory remodeling events in a murine model of asthma: effect of steroid treatment. Am J Physiol 2000;279:L1120-L1128.

29. Hong R, Chakravarti D. The human proliferating cell nuclear antigen regulates transcriptional coactivator p300 activity and promotes transcriptional repression. J Biol Chem 2003;278:44505-44513.

30. Woods AL, Hall PA, Shepherd NA, Hanby AM, Waseem NH, Lane DP, Levison DA. The assessment of proliferating cell nuclear antigen (PCNA) immunostaining in primary gastrointestinal lymphomas and its relationship to histological grade, $\mathrm{S}+\mathrm{G} 2+\mathrm{M}$ phase fraction (flow cytometric analysis) and prognosis. Histopathology 1991;19:21-27.

31. Vignola AM, Chiappara G, Gagliardo R, Gjomarkaj M, Merendino A, Siena L, Bousquet J, Bonsignore G. Apoptosis and airway inflammation in asthma. Apoptosis 2000;5:473-485.
32. Tesfaigzi Y. Roles of apoptosis in airway epithelia. Am J Respir Cell Mol Biol 2006;34:537-547.

33. Jeffery PK. Remodeling and inflammation of bronchi in asthma and chronic obstructive pulmonary disease. Proc Am Thorac Soc 2004;1: 176-183.

34. Anderson SD, Daviskas E. The mechanism of exercise-induced asthma is . . . . J Allergy Clin Immunol 2000;106:453-459.

35. Nucci G, Suki B, Lutchen K. Modeling airflow-related shear stress during heterogeneous constriction and mechanical ventilation. J Appl Physiol 2003;95:348-356.

36. Riley DJ, Rannels DE, Low RB, Jensen L, Jacobs TP. Effect of physical forces on lung structure, function and metabolism. Am Rev Respir Dis 1990;142:910-914.

37. Liu M, Tanswell KA, Post M. Mechanical force-induced signal transduction in lung cells. Am J Physiol 1999;277:L667-L683.

38. Dreyfuss D, Saumon G. Ventilator-induced lung-injury: lessons from experimental studies. Am J Respir Crit Care Med 1998;157:294-323.

39. Trepat X, Puig F, Gavara N, Fredberg JJ, Farre R, Navajas D. Effect of stretch on the structural integrity and micromechanics of human alveolar epithelial cell monolayers exposed to thrombin. Am J Physiol Lung Cell Mol Physiol 2006;290:L1104-L1110.

40. Scichilone N, Morici G, Marchese R, Bonanno A, Profita M, Togias A, Bonsignore MR. Reduced airway responsiveness in non-elite runners. Med Sci Sports Exerc 2005;37:2019-2025.

41. Simon HU, Blaser K. Inhibition of programmed eosinophil death: a key pathogenic event for eosinophilia? Immunol Today 1995;16:53-55.

42. Bratton DL, Fadok VA. "Their's but to do and die": eosinophil longevity in asthma. J Allergy Clin Immunol 1999;103:555-558.

43. Reaves TA, Chin AC, Parkos CA. Neutrophil transepithelial migration: role of toll-like receptors in mucosal inflammation. Mem Inst Oswaldo Cruz 2005;100:191-198.

44. Hansel TT, Walker C. The migration of eosinophils into the sputum of asthmatics: the role of adhesion molecules. Clin Exp Allergy 1992;22: 345-356.

45. Erjefalt JS, Uller L, Malm-Erjefalt M, Persson CG. Rapid and efficient clearance of airway tissue granulocytes through transepithelial migration. Thorax 2004;59:136-143.

46. Beg AA, Baldwin AS. The IкB proteins: multifunctional regulators of Rel/NF-кB transcription factors. Genes Dev 1993;7:2064-2070.

47. Baldwin AS Jr. The NF-кB and IкB proteins: new discoveries and insights. Annu Rev Immunol 1996;14:649.

48. Karin M. How NF-кB is activated: the role of the IкB kinase (IKK) complex. Oncogene 1999;18:6867-6874.

49. Pahl HL. Activators and target genes of Rel/NF-кB transcription factors. Oncogene 1999;18:6853-6866. 